\title{
Behavioral Change Interventions for Aedes Aegypti Mosquito Control in a Semi Urban Area.
}

\author{
${ }^{1}$ Mr. Sumith Sonny Msc(Community Health Nursing), ${ }^{2}$ Mrs. Shiby M Thomas \\ Msc (Community Health Nursing), M.Phil \\ ${ }^{I}$ Nursing TutorAIIMS Rishikesh Associate Professor ${ }^{2}$ Lourdes college of nursing, Ernakulam
}

\begin{abstract}
The population of present study included 165 families residing in a randomly selected semi urban area in Ernakulam district, Kerala, India. The investigator has implemented a strategy of Behavioral change interventions to control aedes aegypti mosquitoes through source reduction which consisted of a Propaganda, Household personal and family counseling and a Mass health education programme. The post test results showed that there is significant reduction in the aedes aegypti mosquito indices of the area.
\end{abstract}

Key words: Behavioral change interventions, aedes aegypti mosquito index.

\section{Introduction}

The mosquito aedes aegypti is the primary vector of three important diseases-dengue, yellow fever, and chikungunya and is capable of transmitting a number of others. Chikungunya and Dengue are two common diseases in Kerala, India, especially during and after the rainy season. Aedes aegypti mosquitoes breed in artificial containers and are found closely associated with human habitat. The best way to control these mosquitoes is source reduction. So the behavioral change interventions aimed at modifying the behavior of the population to control aedes aegypti mosquitoes through source reduction.

\section{Problem statement}

A study to evaluate the effectiveness of Behavioral change interventions in aedes aegypti mosquito control in a semi urban area.

Objectives of the study

- $\quad$ To identify the aedes aegypti mosquito indices of the area.

- To evaluate the effectiveness of behavioral change interventions in aedes aegypti mosquito control.

\section{Methodology}

An evaluative approach was followed in the study and the design adopted was one group pre-test post-test design. The population of present study included families residing in a semi urban area at Ernakulam dstrict, Kerala, India. Sample included 165 families residing in the randomly selected semi urban area at Ernakulam district. The investigator has implemented a strategy of Behavioral change interventions to control aedes aegypti mosquitoes through source reduction.

\section{Behavioral change interventions}

The behavioral change interventions consisted of use of a Propaganda, counseling, Mass health education programme and a Rally or procession involving the families residing in the area. The investigator used the propaganda "Mochanam" which means "freedom or relief". Household personal and family counseling was conducted regarding environmental control of mosquitoes. Leaflets on mosquito control were distributed among the selected population. A mass health education programme and an exhibition were conducted on source reduction and environmental control for mosquito prevention.

\section{Data collection}

The data for the study was obtained through the structured tool which consisted of a checklist to observe the houses and the premises of the selected families. A total of 165 houses and their premises, were the selected families reside were observed, one week before and one week after the behavioral change interventions.

\section{Analysis and interpretations}

There are a lot of entomological monitoring parameters for aedes aegypti mosquitoes.

In this study the investigator has used House Index, Container Index and Breteau Index for monitoring the risk for aedes aegypti borne diseases in the selected population.

- $\quad$ House Index (HI): The percentage of houses positive for aedes aegypti larvae; 
- $\quad$ Container Index (CI): The percentage of water-filled containers positive for aedes aegypti larvae;

- $\quad$ Breteau Index (BI): The number of containers positive for aedes aegypti larvae per 100 houses.

Aedes aegypti mosquito indices were measured before and one week after the implementation of behavioral change interventions which are given in the table below.

Table 1.

Aedes aegypti mosquito indices of the area before and after the implementation of behavioral change interventions.

\begin{tabular}{|c|c|c|c|}
\hline Aedes aegypti indices & Pre test value & Post test value & $\begin{array}{l}\text { Significant levels of risks for } \\
\text { mosquito borne diseases }\end{array}$ \\
\hline House index & $\begin{array}{l}76.96 \\
\text { (high risk) }\end{array}$ & $\begin{array}{l}1.82 \\
\text { (low risk) }\end{array}$ & $\begin{array}{l}>10-\text { high risk } \\
10 \text { to } 1 \text { - moderate risk } \\
<1 \text { - low risk }\end{array}$ \\
\hline Container index & $\begin{array}{l}32.5 \\
\text { (high risk) }\end{array}$ & $\begin{array}{l}3.66 \\
\text { (low risk) }\end{array}$ & $\begin{array}{l}>5-\text { high risk } \\
\leq 5-\text { low risk }\end{array}$ \\
\hline Breteau index & $\begin{array}{l}172.73 \\
\text { (high risk) }\end{array}$ & $\begin{array}{l}1.82 \\
\text { (low risk) }\end{array}$ & $\begin{array}{l}>5-\text { high risk } \\
\leq 5-\text { low risk }\end{array}$ \\
\hline
\end{tabular}

The post test results showed that there is significant reduction in the mosquito indices of the area. So the behavioral change interventions are effective in modifying the behavior of the population there by controlling aedes aegypti mosquitoes through source reduction and reducing the risk for mosquito borne diseases in the selected population.

\section{Reference}

[1]. Urban mosquito control - a case study. Icmr bulletin [ Internet]. 2000 Mar [ Cited 2011 Jan 26] ; 30(3) : Available from URL: http://www.icmr.nic.in/bumar2000.pdf.

[2]. Nathan M B, Lloyd L, Wiltshire A. Community Participation in Environmental Management for Dengue Vector Control: Experiences from the English-speaking Caribbean. Dengue Bulletin [Internet]. 2004 [Cited 2011 Feb 13 ] ; 28: Available from URL : http://www.searo.who.int/LinkFiles/Dengue_case_study_2_caribbean_.pdf

[3]. Pe'rez D, Lefe'vre P, Sa'nchez L, Sa'nchez L M, Boelaert M, Kourı' G et al. Community participation in Aedes aegypti control: a sociological perspective on five years of research in the health area " 26 de Julio", Havana, Cuba. Tropical Medicine and International Health [Internet]. 2007 May [ Cited 2011 Jan 26]; 12(5): Available from URL: http://dspace.itg.be/bitstream/10390/1391/1/2007tmih0664.pdf 